\section{Control of the Fluorine Hazard}

\section{J. D. PATERSON}

\section{From the Medical Department, Imperial Chemical Industries Ltd., General Chemical Division}

In view of the ever increasing number of industrial applications of fluorine-containing compounds, and the dearth of references to its effects in the literature, an account of factory experience may be of interest.

The most common references to fluorine have been with regard to the controversy as to whether or not water supplies should have fluorine compounds added as a means of reducing the incidence of dental caries in children. This paper deals, however, with hydrofluoric acid, which is quite a different proposition from the sodium silico-fluoride generally used in the fluoridation of water.

Experience with the very reactive compounds of fluorine leads us to the view that, considering only the acute effects and ignoring the chronic effects, they are even more severe in their action than mustard gas.

In the design of plant the following points should be borne in mind:

(1) The possibility of the material coming in contact with the operators should be reduced to the minimum.

(2) Adequate protective clothing should be provided so that if the material does come in contact with the operator no adverse effects are produced.

(3) Means of decontaminating or treating the operator should be available if, by mischance, he does come in contact with the material.

(4) There should be effective medical supervision.

The hazard with hydrofluoric acid is both acute and chronic. The acute hazard is that in concentrations of over $20 \%$ it will cause damage to body tissue, and in concentrations of over $60 \%$ this damage will be immediately apparent.

Like other acids in contact with the skin, it will cause dehydration and corrosion. It has, however, in addition to these, a unique effect. The fluorine ion will penetrate the deep layers of the tissue and will exert a dissolving action on the cellular membranes, causing a liquescent necrosis which, when it reaches bone, causes decalcification. The more concentrated the acid, the longer the period of contact and the more delicate the tissue, the more rapid in onset and the more intense will be the pain phenomena and the deeper will be the necrosis.

The chronic hazard is the possibility of the development of fluorosis, which is a condition of sclerosis of bone, and in extreme cases of ossification of the ligaments.

How, then, can these hazards, the acute and the chronic, be controlled?

First consideration must be given to ways and means of confining the material to the interior of the plant; this is the province of the engineers and chemists, but they require and seek the advice of the industrial medical officer about the dangers to which operators might be exposed. It is at the design stage that much can be done to eliminate hazards by remembering that it is easier and cheaper to incorporate safety devices during construction

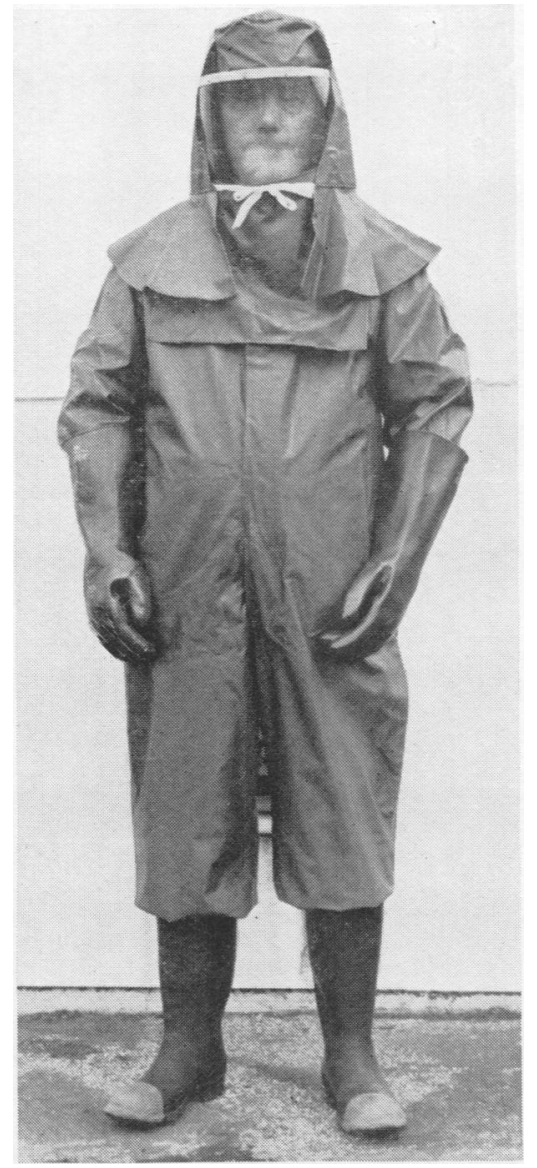

Fig. 1.-Photograph showing type of protective clothing worn by operators on the high fluoridation plant when engaged in work which might expose them to heavy contamination.

than after completion, and that good design goes a long way towards preventing accidents.

The reactivity of hydrofluoric acid is probably sufficient in itself to make the design staff do all in their power to keep the material enclosed, if only for technical reasons, as not only does it attack body tissue but also a diversity of normal construction materials. Such plant, therefore, is well on its way to being leak-proof without our even considering the medical point of view. The chance of leakage must, nevertheless, be kept in mind as it is impossible to neutralize. Some means of diluting any fume to a concentration at which it would be harmless is also essential. This is done by building the plant virtually in the open air.

The next point is how to protect the worker. It is our experience that once a man is convinced that the risks are serious he will wear the protective clothing provided, and indeed will complain if he does not consider it sufficient. No persuasion is necessary if the material is 


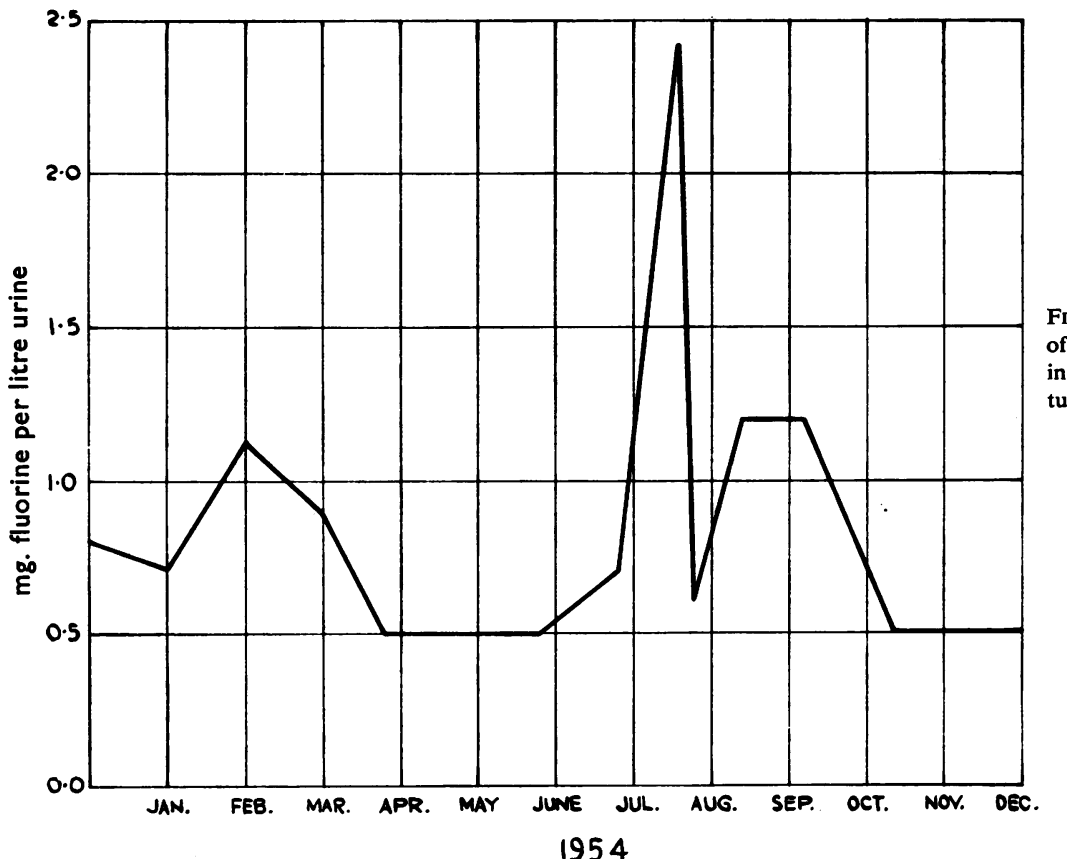

Fig. 2.-Graph showing excretion rate of fluorine in milligrams per litre of urine in process workers illustrating rapid return to normal after a rise in rate.

such as hydrofluoric acid, sodium, or hydrochloric acid, but it is a little more difficult with, for example, benzene, where the risk is not so obvious.

In the early days it was decided that full protective clothing should be worn at all times, but it was considered that it would be a burden on the men to wear indefinitely this outfit, consisting of woollen suit, oilskin coat, rubber boots, gloves, and headpiece. The dangers were explained to the men and an undertaking given that the clothing would be modified as soon as it was considered safe to do so. After about six months the protection was reduced to overalls, boots, gloves, and headpiece (Fig. 1) with the full rig-out beirg used only on breakdowns and special maintenance work.

It is imperative, on a plant which requires extensive protective clothing to be worn, to provide changing and messing accommodation close at hand. This is built as a separate block into which is incorporated a first-aid room with shower baths and an alarm system to alert the Medical Department and summon a nurse.

Where protective clothing is worn a system of inspection and repair must be organized, particularly with regard to gloves, which have the hardest wear. The majority of burns have been due to penetration of a glove through a pin hole, ard to reduce such risks as much as possible the gloves used on the plant are inspected daily and withdrawn from service if any flaw is noted.

Protective clothing furnishes a defence against the acute effects of hydrofluoric acid, and we are confident that, with normal operating, the possibility of fluorosis developing is remote. Nevertheless, when special maintenance is required and parts which are heavily con- taminated are being handled, the risk is present. It is overcome by wearing full protective clothing and also a fresh-air hood, to prevent the inhalation of fumes.

The system of medical supervision employed is designed to draw attention to chronic effects in workers at an early stage. Before being employed on the plant, operatives are required to pass a medical examination. At this examination, which includes a radiological examination of the chest, spine, and pelvis, those who show abnormalities of heart, lungs, or skeleton are excluded, as are those of low mentality or hyperexcitability, or who have very defective vision.

When the plant first began producing each operator had a weekly urine test and an estimation of the fluorine content was made. It is known that if this content does not exceed $10 \mathrm{mg}$./ $/$. the possibility of fluorosis developing is slight. It is our policy to take a figure of $1 \mathrm{mg} . / 1$. as a reasonable and safe excretion rate.

These estimations were, in the first instance, carried out weekly, but the excretion rate of fluorine is so high and a return to normal level so quick, that there was a chance of missing a raised level unless they were done daily. After a little time it was apparent that the excretion rates were satisfactory, and it was decided to test the men not so much as individuals, but as a check on each part of the plant at weekly intervals. A rota which ensures that each job is covered weekly is now in operation and has been a great help as an indicator to the plant supervisors of points requiring attention which would otherwise remain unnoticed.

Each operative has a blood examination every six months, a clinical examination yearly, and biennial repeat radiograph of the chest, spine, and pelvis. At one 
time they had dental examinations every six months, but these have been discontinued.

In spite of all these precautions we still occasionally have to treat burns due to hydrofluoric acid, but we have been fortunate in that we have never had a really serious burn, nor have we had a burn of the eye.

In all cases the symptoms are the same. There is a feeling of tingling over the affected area, followed by throbbing and severe pain. These symptoms may be delayed for some hours or they may occur very quickly, depending on the strength of the hydrofluoric acid and the duration of contact. In either case the pain is agonizing.

What happens when a man is burned ? First of all he is instructed to wash the part under copious amounts of water and then a dressing of magnesium oxide paste is applied and rubbed in. This, in the very mild burns, is usually sufficient. In the more severe burns, however, the standard treatment adopted is the injection of $10 \%$ calcium gluconate into and around the burned area until a weal is formed. It is very pleasing to see the relief from pain which this gives-in many cases before the injection is complete.

The men know of this relief and even if they have gone home before the onset of symptoms they will still come into the Works for treatment. It has been suggested that it may be necessary to give either a general or a local anaesthetic before injecting. My experience with burns we have had has been that it has not been necessary. Perhaps this is due to the cooperation we get from the men, who are prepared to suffer some discomfort during injection as they know of the relief which it brings, and also to the relatively minor nature of the burns. I can well imagine, however, that without this cooperation, or with severe burns, anaesthesia might be necessary. Most promising clinical trials are being carried out with a new anaesthetic called "fluothane". In the future, if anaesthesia is necessary, we may be giving one fluorine compound in order to relieve the effects of another.

Other compounds, including chlorine and bromine tri-fluorides, are also very reactive; so much so that in contact with the skin only thermal burns occur without the penetrating effect shown by hydrofluoric acid. Fluorine refrigerants and fluorocarbons give rise to no hazard except in so far as the handling of the elementary fluorine used in their manufacture is concerned.

A discussion followed on the mechanisms by which the relief given by magnesium oxide and calcium gluconate might be explained, but beyond the fact that magnesium fluoride was insoluble and that magnesium hydroxide was particularly effective when mixed with glycerol, no definite conclusions could be reached.

It was stated that sodium silico-fluoride gave a severe skin reaction; this substance is used in the manufacture of latex foam and for destroying vermin.

The minimal concentration of hydrofluoric acid likely to be hazardous was discussed, and it was claimed that noticeable effects could be produced by $3 \%$ solution with long exposure. Below $20 \%$ pain was caused but no burning. Long experience in a workshop where glass was etched with hydrofluoric acid had revealed no sign of trouble.

It was considered that the intake of vapour by inhalation was likely to be too low to cause fluorosis, which was probably associated with ingestion over a long period. Sixty to $70 \%$ of the intake is normally excreted.

BibliogRAPHY

Bartalini, E., and Grianti, V. (1953). Rass. Med. industr., 22, 34.

Dale, R.'H. (1951). Brit. med.J., 1, 728

Jones, A. Thelwall (1939). J. industr. Hyg., 21, 205.

Jones, A. Thelwall (1939). J. industr. Hyg., 21, 20
Schuermann, H. (1937). Derm. Wschr., 104, 661.

\section{B.M.A. Occupational Health Prize}

The Occupational Health Prize was established by the Association for the purpose of encouraging interest and research in the field of occupational health. The Council of the British Medical Association is prepared to consider the award of this Prize which consists of a certificate and $£ 50$ in the year 1957.

Any member of the Association who is engaged in the practice of occupational health, either whole-time or part-time, is eligible to compete for the prize. Candidates may select their own subject.

Entries should be submitted in a form suitable for publication and must include personal observations and experiences collected by the candidates in the course of their work. If no entry is of sufficient merit no award will be made. Candidates should confine their attention to their own observations rather than to comments on previously published work on the subject, though reference to current literature should not be omitted when it bears directly on their results, their interpretations, and their conclusions.

Essays, or whatever form the candidate desires his work to take, must be sent to the Secretary, British Medical Association, B.M.A. House, Tavistock Square, London, W.C.1, not later than January 31, 1957.

No study or essay that has been published in the medical press or elsewhere will be considered eligible for the prize, and a contribution offered in one year cannot be accepted in any subsequent year unless it includes evidence of further work. A previous prizewinner is not precluded from entering.

If any question arises in reference to the eligibility of the candidate or the admissibility of his or her essay, the decision of the Council on any such point shall be final.

Preliminary notice of entry for this competition is required on a form of application to be obtained from the Secretary.

Each entry must be typewritten or printed on one side of the paper only, and accompanied by a note of the candidate's name and address.

No definite limits are laid down as to the length of essays, but the Council anticipates that for this Competition, essays should consist of between 3,000 and 10,000 words.

Enquiries relative to the prize should be addressed to the Secretary. 